\title{
OS PARAMETROS CURRICULARES NACIONAIS (PCN) E A EDUCAC̄ÃO BRASILEIRA SOB A SUPREMACIA DO MERCADO
}

\section{Luciano Accioly Lemos Moreira}

\section{RESUMO}

O presente trabalho analisa, à luz da ontologia marxiana, a formação voltada para a empregabilidade contida nos Parâmetros Curriculares Nacionais (1998/1999), nos Temas Transversais (1998) e nas Diretrizes Curriculares Nacionais do Ensino Médio (1999). A abordagem defendida pelos Parâmetros Curriculares Nacionais apresenta a sociabilidade do capital como algo insuperável e intocável, cabendo apenas transformar a consciência dos homens, capacitando-os para o enfrentamento dos desafios de um mundo tecnologicamente desenvolvido e economicamente mundializado. A critica realizada por nossa análise, pauta-se na explicitação das implicações e limites dessa proposta para a formação humana, compreendendo que a proposta dos documentos analisados mantém os efeitos do trabalho alienado sobre o trabalhador, legitimando e naturalizando a desumanização inerente às relações sociais da sociabilidade capitalista. Quanto à vida coletiva, os Parâmetros Curriculares Nacionais e os Temas Transversais sugerem a cidadania e o mercado consumidor. Entendemos que essa vida coletiva tem uma existência abstrata e vazia de sentido, pois restringe-se ao espaço da política e do mercado, controlados e necessários à reprodução desse sistema. E por fim, tentamos demonstrar as possibilidades de uma atividade educativa que vislumbre uma formação para além do capital.

\section{PALAVRAS-CHAVE}

Empregabilidade; Cidadania; Mercado consumidor; Formação humana

\section{THE NATIONAL CURRICULAR PARAMETERS (PCN) AND THE BRAZILIAN EDUCATION UNDER THE SUPREMACY OF THE MARKET}

\begin{abstract}
The present work analyzes, to the light of the marxiana ontologia, the formation directed toward the empregabilidade contained in the National Curricular Parameters (1998/1999), in the Transversal Subjects (1998) and in the National Curricular Lines of direction of Average Ensino (1999). The boarding defended for the National Curricular Parameters presents the sociability of insuperável and untouchable the capital as something, fitting only to transform the conscience of the men, enabling them to the enfretamento of the challenges of a world tecnologicamente developed and economically mundializado. It criticizes it carried through for our analysis, guideline in the explicitação of the implications and limits of this proposal for the formation human being, understanding that the proposal of analyzed documents keeps the effect of the mentally ill work on the worker, legitimizing and naturalizing the inherent desumanização to the social relations of the capitalist sociability. How much to the collective life, the National Curricular Parameters and the Transversal Subjects suggest the citizenship and the consuming market. We understand that this collective life has an abstract and empty existence of direction, therefore restricts it the space of the politics and the market, controlled and necessary to the reproduction of this system. E finally, we try to demonstrate the possibilities of an educative activity that has glimpsed a formation for beyond the capital
\end{abstract}

\section{KEYWORDS}

Empregabilidade; Citizenship; Consuming market; Formation human being 
A partir dos anos 90, as diretrizes para a formação escolar no Brasil sofrem alterações em todos seus aspectos: legais, avaliativos, curriculares e pedagógicos. Com a instauração, em 1996, da Lei de Diretrizes e Bases da Educação (9394/96), designada Lei Darcy Ribeiro, várias reformas são aplicadas na estrutura educacional brasileira. Essa nova onda de "mudanças", por parte das políticas educacionais, estende-se e proporciona a elaboração de outros documentos. Para exemplo disso, temos a composição dos Parâmetros Curriculares Nacionais $(1998 ; 1999)$ em vários níveis de ensino, as Diretrizes Curriculares Nacionais (1999) entre outros, demonstrando que, de alguma maneira, a formação do educador e do educando estavam em processo de reestruturação.

Os PCN (1998, p.9) se constituem numa "proposta de reorientação curricular”, na qual as "secretarias de educação, escolas, instituições formadoras de professores, instituições de pesquisa, editoras e todas as pessoas interessadas em educação, dos diferentes estados e municípios brasileiros" precisam conhecer esse "novo" guia curricular, para responder às necessidades formativas dos indivíduos em um mundo contemporâneo, em constante transformação. Essa reestruturação formadora advogada pelo governo brasileiro, demonstra ter um caráter amplo, pois atinge todos os níveis de ensino, pesquisa e produção de livros didáticos; alertando-nos para a análise dos motivos dessa "transformação escolar", dado a amplitude dessa reforma na educação brasileira.

Os Parâmetros Curriculares Nacionais abrangem toda a educação básica, desde as séries iniciais, de $1^{\mathrm{a}}$ a $4^{\mathrm{a}}$, ao fim do Ensino Fundamental e Médio. Os PCN's foram organizados em uma série de livros ou cartilhas que orientam todas as disciplinas (História, Geografia, Português...), como também, há entre esses livros, os conteúdos e temas chamados Transversais, que deverão ser trabalhados de forma interdisciplinar em cada série. Analisaremos, assim, os princípios que norteiam a formação escolar nos Parâmetros Curriculares Nacionais do Ensino Fundamental - de $5^{\text {a à }} 8^{\mathrm{a}}$ série (1998) e os Parâmetros do Ensino Médio $-1^{\circ}$ à $3^{\circ}$ ano (1999). Utilizando, também, o tema Transversal denominado “Trabalho e Consumo”, contido nos PCNs do Ensino Fundamental (1998), já que esse tema está diretamente relacionado ao objeto de pesquisa desse trabalho: a empregabilidade. Além desses documentos, iremos analisar as Diretrizes Curriculares Nacionais do Ensino Médio (1999) sobre a mesma problemática em questão, a fim de determos um olhar mais amplo 
sobre essas políticas educacionais do governo brasileiro, aplicado como forma de o Brasil sintonizar-se com as exigências da economia mundializada.

\title{
A EMPREGABILIDADE COMO EIXO CENTRAL DOS PCN
}

A formação escolar, defendida pelos Parâmetros Curriculares Nacionais (1998;1999), parte de uma constatação no que o mundo contemporâneo transformou-se e, portanto, a educação no Brasil também deve mudar. Torna-se evidente tal questão, quando em um texto inserido nos PCN do ensino fundamental (1998), o então Ministro da Educação e do Desporto, Paulo Renato Souza, ratifica o papel que a educação deve ter nesse momento no Brasil:

\begin{abstract}
O papel fundamental da educação no desenvolvimento das pessoas e das sociedades amplia-se ainda mais no despertar do novo milênio e aponta para a necessidade de se construir uma escola voltada para a formação de cidadãos. Vivemos numa era marcada pela competição e pela excelência, em que progressos científicos e avanços tecnológicos definem exigências novas para os jovens que ingressarão no mundo do trabalho. Tal demanda impõe uma revisão dos currículos, que orientam o trabalho cotidianamente realizado pelos professores e especialistas em educação do nosso país. (PARÂMETROS CURRICULARES NACIONAIS, 1998, p.5).
\end{abstract}

De acordo com o recorte, competição e excelência mantêm uma relação de reciprocidade, pois, no caso da primeira, representaria uma lei natural na socialidade humana, e saudável para as relações do mercado do capital; a segunda, denotaria a importância do investimento em educação nos indivíduos, os capacitando com um maior desenvolvimento do seu capital humano, imprescindível na conquista por um emprego.

A implantação dessa formação para a ocupação de postos de trabalho modernizados exige do Brasil, conforme os PCN, uma superação de suas desigualdades sociais e políticas adquiridas historicamente. Pois, neste fim de milênio:

os dividendos das importantes descobertas e dos progressos científicos da humanidade convivem com desencantamento e desesperança, alimentados por problemas que vão do aumento do desemprego e do fenômeno da exclusão, inclusive nos países ricos, à manutenção dos níveis de desigualdade de desenvolvimento nos diferentes países . $\mathrm{O}$ aumento das interdependências entre nações e regiões contribuiu para colocar o foco nos diferentes desequilíbrios, entre ricas e pobres, como também entre 'incluídos' e 'excluídos' socialmente, no interior de cada país; com a extensão dos meios de informação e de comunicação evidenciaram-se também, modos de vida e de consumo de uma parcela dos habitantes do planeta em contraposição a situações de miséria extrema (PARÂMETROS CURRICULARES NACIONAIS, 1998, p.15). 
A constatação dos problemas da modernização é inicialmente colocada de uma forma geral, para depois especificar o atraso brasileiro restrito ao campo da educação. A formação escolar deve acompanhar o progresso tecnológico e econômico já existente no Brasil. Tornase explicito tal questão quando os PCN's afirmam que:

\begin{abstract}
Neste final de milênio, a sociedade brasileira vive um momento de rápidas transformações econômicas e tecnológicas, ao mesmo tempo em que os avanços na cultura e na educação transcorrem de forma bastante lenta. Em função de uma economia dependente, não se desenvolveu uma cultura e um sistema educacional que pudesse fortalecer a economia, fazendo-a caminhar para a auto-suficiência. (PARÂMETROS CURRICULARES NACIONAIS, 1998, p.19).
\end{abstract}

A educação ocupa, a partir dessas políticas, o lugar central na resolução do atraso a qual o Brasil se encontra na atualidade. O conhecimento, por meio da formação escolar, se constitui em requisito imprescindível no desenvolvimento do ser humano e, conseqüentemente, da economia. O desenvolvimento tecnológico, científico e produtivo do Brasil, conforme os PCN's (1998,) foram alcançados de forma rápida, porém tardia e dependente em relação aos países avançados. Contudo, conforme tais documentos, o que está no momento entravando a expansão da economia brasileira em direção à sua auto-suficiência, se explica pela falta de uma cultura voltada para a formação de competências e habilidades, indispensáveis a um desenvolvimento auto-sustentável na direção de uma maior competitividade mundial.

Além da necessidade de formar indivíduos conscientes de seus direitos políticos, a outra finalidade da educação, e não menos importante, é uma melhor qualificação dos educandos para o mercado de trabalho, que pode ser resumido na formação para a garantia da empregabilidade.

Torna-se explícito que o conhecimento do mundo atual, ou seja, a compreensão do que é necessário fazer, pensar e agir em face das modificações tecnológicas e organizacionais do capital na atualidade, coloca-se como o cabedal necessário e indispensável na preparação dos educandos no confronto com a realidade competitiva do capital inexorável à transformação humana.

A formação voltada às exigências do capitalismo em processo de reestruturação, atinge todo o ensino básico, pois não apenas os PCN's do Ensino Fundamental (1998) 
cumprem essa função, como os Parâmetros do Ensino Médio (1999) conduzem para esse mesmo intuito. Conforme, esse documento, o Ensino Médio no Brasil está mudando:

A consolidação do Estado democrático, as novas tecnologias e as mudanças na produção de bens, serviços e conhecimentos exigem que a escola possibilite aos alunos integrarem-se ao mundo contemporâneo nas dimensões fundamentais da cidadania e do trabalho. (PARÂMETROS CURRICULARES NACIONAIS ENSINO MÉDIO, 1999, p.11).

Para os PCN (1999) do Ensino Médio, o avanço econômico do Brasil, a formação de um estado democrático e a introdução do país ao mundo tecnologicamente desenvolvido, possibilitaram a construção de um livre mercado e no surgimento de bens, serviços e setores novos na economia brasileira. Há, nesse instante, uma outra organização produtiva do capital cada vez mais desenvolvido tecnologicamente e, consequentemente, surge à necessidade de uma nova formação humana para essa realidade. A explicação dessa questão, de acordo com os PCN é a seguinte:

\footnotetext{
Nos anos 60 e 70 [...] o nível de desenvolvimento da industrialização na América Latina, a política educacional vigente priorizou, como finalidade para o Ensino Médio, a formação de especialistas capazes de dominar a utilização de maquinarias ou de dirigir processos de produção. Esta tendência levou o Brasil, na década de 70, a propor a profissionalização compulsória, estratégia que também visava a diminuir a pressão da demanda sobre o Ensino Superior. (PARÂMETROS CURRICULARES NACIONAIS, 1999, p.14).
}

Com o fim da década de 80 e início dos anos 90, o trabalhador, conforme os PCN's, deve capacitar-se para enfrentar

[...] um desafio de outra ordem. O volume de informações, produzido em decorrência das novas tecnologias, é constantemente superado, colocando novos parâmetros para a formação dos cidadãos. Não se trata de acumular conhecimentos. A formação do aluno deve ter como alvo principal a aquisição de conhecimentos básicos, a preparação científica e a capacidade de utilizar as diferentes tecnologias relativas às áreas de atuação. (PARÂMETROS CURRICULARES NACIONAIS, 1999, p.14).

Essa educação vai pautar-se por uma "formação geral, em oposição à formação específica; o desenvolvimento da capacidade de pesquisar, buscar informações, analisá-las e selecioná-las; a capacidade de aprender, criar, formular, ao invés do simples exercício de memorização" (PARÂMETROS CURRICULARES NACIONAIS, 1999, p.14). A educação deverá atender, com isso, aos padrões de qualidade e de conhecimentos que coadunem com as necessidades do mercado de trabalho desta "nova" sociedade. A realidade imediata, 
inconstante e diariamente modificável se coloca como o único patamar a ser visualizado pelo trabalhador atual. Nessa realidade, não há passado nem futuro. O presente ameaçador e desconhecido deve ser instantaneamente conhecido pelos indivíduos, adequando-os a nova realidade. Esse movimento aprisiona os homens à solução de problemas parciais, localizados e restritos à sobrevivência na sociabilidade do capital.

Nos Parâmetros Curriculares Nacionais (1999, p.25) encontramos a defesa de uma formação para o mercado de trabalho, que supere a conformação da antiga educação dos trabalhadores no taylorismo, já que, na atualidade, "o desenvolvimento das competências cognitivas e culturais exigidas para o pleno desenvolvimento humano passa a coincidir com o que se espera na esfera da produção". Assim, "as competências desejáveis ao pleno desenvolvimento humano aproxima-se das necessárias à inserção no processo produtivo" (idem, ibdem, 1999, p.26). Podemos, então, afirmar que a partir dessa citação, o capital oferece, diante de suas necessidades materiais e espirituais, as condições reais de uma formação integral e humanizadora para os trabalhadores e cidadãos da atualidade. Desse modo, por mais perversa que se apresente a realidade atual, para os PCN's, essas dificuldades representam estímulos geradores do crescimento pessoal.

A educação deve conduzir os indivíduos para uma melhor perspectiva de empregabilidade, mesmo que essa possibilidade de vida ativa no trabalho, não seja garantida, visto que, de acordo com os Parâmetros, "a aproximação entre as competências desejáveis em cada uma das dimensões sociais não garante uma homologação das oportunidades sociais." Nesta ótica, há que considerar a redução dos "espaços para os que vão trabalhar em atividades simbólicas, em que o conhecimento é o instrumento principal, os que vão continuar atuando em atividades tradicionais e, o mais grave, os que se vêem excluídos" (PARÂMETROS CURRICULARES NACIONAIS, 1999, p.26, grifo no original). A realidade do progresso capitalista é compreendida como uma força inalterável, na qual o rolo compressor do desemprego pode atingir qualquer um. Por conseguinte, atingirá, com certeza, de acordo com os PCN's, os que não tiverem "acesso a uma educação que contribua efetivamente para a sua incorporação" (1999, p.26, grifo do autor).

Se observarmos mais atentamente, perceberemos que as competências vão muito além de conhecimentos a serem apreendidos, já que é necessário desenvolver comportamentos, habilidades, valores e estado emocional nos educandos, preparando-os para um mercado de trabalho arriscado, em contínua mutação. O emprego precarizado, 
subcontratado e terceirizado deve ser enfrentado com criatividade, curiosidade e capacidade de criar múltiplas alternativas. Essas competências irão desenvolver capacidades imprescindíveis na realização das funções inerentes aos empregos existentes, como também, na formação de uma estrutura emocional nos trabalhadores que os faça suportar uma vida sem emprego. Uma outra aptidão exigida por essa formação é a criatividade. Essa habilidade além das muitas utilidades para o sistema produtivo, em sua última instância, coloca-se como uma saída para o desempregado, pois, o uso da criatividade poderá levar os trabalhadores desempregados a criarem novas formas de empregos, recolocando-se, assim, novamente na vida produtiva, desobrigando o Estado e o capital da responsabilidade pelo desemprego crônico.

As Diretrizes Curriculares Nacionais do Ensino Médio (1999, p.102) demonstram essa expectativa, quando explicitam que "as competências e habilidades requeridas por uma organização da produção na qual criatividade, autonomia e capacidade de solucionar problemas serão cada vez mais importantes comparadas à repetição de tarefas rotineiras". Os PCN proporcionam uma qualificação do trabalhador para o desespero do desemprego crônico, apontando como possibilidade uma formação metamorfoseadora, ou seja, o indivíduo deve estar preparado para constantemente moldar-se as mudanças do mercado de trabalho. $\mathrm{O}$ capital humano na era da empregabilidade, não se restringe ao aprendizado de funções técnicas e repetitivas voltadas ao pleno emprego taylorita. É imprescindível na atualidade, a formação de competências que habilitem os indivíduos à sobrevivência numa época de incertezas do toyotismo.

Os indivíduos devem adquirir o espírito inovador de uma época em que a criatividade deve superar idéias tradicionais tão combatidas pelos PCN (1998/1999). Ser tradicional é desejar o pleno emprego, que, no momento de crise do capital, não se apresenta como possibilidade. Deve-se, portanto, criar, expandir, inventar trabalho ou formas empreendedoras individualizadas de ganhar a vida no mercado competitivo do capital.

Empregabilidade, competência e flexibilidade são as novas categorias que passam a orientar a formação escolar, visando atender às necessidades econômicas, políticas e ideológicas do capital em crise, que "surgem não só como tentativa de melhor adequar a educação aos imperativos da nova ordem econômica" (OLIVEIRA, 2003, p.32), mas principalmente, desviar ideologicamente a problemática do desemprego de seu eixo central. É na materialidade das relações do capital que se dá a existência desse problema. 
$\mathrm{O}$ processo de adaptação dos educandos à realidade do desemprego e da concorrência passa por uma formação geral, em que a totalidade do trabalhador, ou seja, sua disposição física, emocional e espiritual, esteja completamente subordinada aos imperativos do capital. Por conseguinte, nessa formação "a criatividade, o espírito inventivo, a curiosidade pelo inusitado, a afetividade [...]" devem habilitar os indivíduos com capacidades de "suportar a inquietação, conviver com o incerto, o imprevisível e o diferente" (DIRETRIZES CURRICULARES NACIONAIS, 1999, p.110, grifo do autor). A educação, nesse momento, não deve formar trabalhadores que usem apenas sua força física e intelectiva para o mercado, mas também, seus desejos, afetividades, sonhos, enfim, sua subjetividade é incorporada aos ditames e desejos do capital. No instante que o capital atravessa uma crise estrutural e os níveis de desemprego são altíssimos e constantes, é necessário formar indivíduos criativos e inventivos, com o objetivo de induzi-los a descoberta de uma solução eficaz para seus problemas. A eficácia deve estar contida na melhor adaptação dos trabalhadores as circunstâncias do momento. Outro ponto dessa formação é nivelar a relação entre trabalho e capital. O trabalhador, não mais se percebe como antagônico ao capital, mas associado ou colaborador desse sistema sociometabólico. As relações do capital sobre o trabalho nos dias atuais desenvolvem formas diferenciadas, as quais se complexificam, ocultando a exploração do homem pelo homem, passando uma idéia de empreendedorismo, colaborador, associado. Enfim, o trabalho alienado, produtor de maisvalia e fundado na venda e compra de força de trabalho, é encoberto por uma neblina mistificadora de uma outra época para além do emprego tradicional. O fim das classes sociais, apontado implicitamente no discurso dos PCN, qualifica os trabalhadores e os capitalista em iguais partícipes no construto do mundo da mercadoria. O trabalhador proprietário de si mesmo, assume total responsabilidade no seu sucesso ou fracasso na vida produtiva capitalista. Marx (2002, p.78), contudo, atinge certeiramente o âmago dessa questão, pois conforme a citação:

O trabalhador, em relação ao patrão, não se encontra de modo nenhum na situação de vendedor livre... o capitalista é sempre livre para empregar o trabalho e o operário vê-se obrigado a vendê-lo. O valor do trabalho fica completamente aniquilado se não for vendido a todo o momento. $O$ trabalho não pode ser nem acumulado nem poupado, ao contrário das autênticas mercadorias. O trabalho é vida, e se a vida não for permutada por alimento, depressa sofre danos e morre. Para que a vida do homem seja uma mercadoria, deve então admitir-se a escravidão. Por essa razão, se o trabalho é uma mercadoria, surge como mercadoria da mais miserável espécie. Mas até segundo os princípios econômicos, ele não é mercadoria, uma vez que não é o livre resultado de um mercado livre. O sistema econômico atual 'reduz ao mesmo tempo o preço e a remuneração do trabalho, aperfeiçoa o trabalhador e 

(MARX, 2002, p.78).

O trabalhador, conforme Marx, não pode viver sem trabalho, pois ao se tornar desempregado, ou seja, se não conseguir quem compre sua força de trabalho e conceda uma pequena parcela dessa relação de produção em forma de salário, ele morrerá. Essa relação antagônica torna-se nítida quando percebemos a estrutura de classe em que se assenta a sociabilidade do capital, visto que para Marx (2003, p.80) "o capital é então o poder de domínio sobre o trabalho e sobre os seus produtos. O capitalismo tem este poder, não em razão das suas virtudes pessoais ou humanas, mas como proprietário do capital". Continuando, ele afirma que, "O seu poder é o poder de compra do seu capital, a que nada se pode contrapor". Nessa proposição, as coisas são colocadas em seus devidos lugares - o capitalista, dono dos meios de produção, domina o trabalhador, pois este tem sua existência aprisionada a uma relação social que o explora diariamente.

A formação para a empregabilidade representa-se numa apreensão, por parte dos futuros trabalhadores, de valores, comportamentos, conhecimentos e emoções imprescindíveis à reprodução do sistema do capital. Essa formação não garantirá o emprego, no entanto, assegurará a constituição de um indivíduo preparado a se conformar, ou com os empregos precários cada vez mais freqüentes, ou com a existência do desemprego que o levará a sentirse culpado por sua má qualificação. Apelando para as explicações irônicas do capital da atualidade, quem sabe a criatividade e a autonomia exigida dessa nova formação não possibilite uma outra alternativa de trabalho, pois o desempregado poderá, inventar trabalho, e dessa forma ser um empreendedor.

A saída para o indivíduo, observada pelos PCN (1998;1999), é a construção de uma outra espécie de trabalhador, uma vez que a formação fundamentada na organização taylorista, torna-se obsoleta para a produção do capital no toyotismo. Assim, os que ainda não ingressaram no mundo do trabalho e os que já fazem parte da vida ativa do país devem ressignificar suas habilidades e conhecimentos, a fim de incorporar-se possivelmente no mercado capitalista.

Empregabilidade é, portanto, formar-se para um mundo da incerteza, do trabalho precário e do desemprego. Nesse tormento, vislumbra-se como única saída a reflexão individualista burguesa. É o indivíduo que precisa mudar, melhor formar-se, qualificar-se, ser 
mais competente, desenvolver suas inteligências, enfim, o trabalhador deve ser culpabilizado para que a sociabilidade do capital com todo o seu corolário continue intocável em seu movimento destrutivo.

\section{OS PCN E A RELAÇÃO ENTRE A EMPREGABILIDADE E CIDADANIA}

A proposta da formação para a empregabilidade, ou seja, para o desespero do desemprego crônico, necessita, para se tornar ideologicamente viável, articular-se com a construção de um homem politicamente ativo, porém restrito ao espaço da cidadania. $\mathrm{O}$ trabalhador deve ter como horizonte de sua luta social, o espaço controlado pelo capital. Com isso, nossa crítica irá analisar essa articulação e explicitar os limites e as possibilidades dessa formação. Conforme os Parâmetros Curriculares Nacionais, devemos:

Compreender a cidadania como participação social e política, assim como exercício de direitos políticos, civis e sociais, adotando, no dia-a-dia, atitudes de solidariedade, cooperação e repúdio às injustiças, respeitanto o outro e exigindo para si o mesmo respeito. (PARÂMETROS CURRICULARES NACIONAIS, 1998, p.55).

A participação social deve se fixar no âmbito da política. A força social dos sujeitos históricos irá convergir para uma ação política, na qual os direitos e deveres sociais, civis e políticos regulamentarão os limites e possibilidades das conquistas sociais. As lutas sociais pelo viés da cidadania serão equilibradas pela prática da justiça, da solidariedade e da cooperação. Exceder esses limites é ferir o contrato social da liberdade individual, em que a liberdade de um termina na liberdade do outro. Por esse prisma, a liberdade tem seu fundamento na manutenção e respeito da propriedade privada. O capitalista, dono dos seus meios de produção, e o trabalhador, proprietário do seu capital humano, cumprem na mesma medida, suas funções para a produção de mercadoria e, harmoniosamente, participam desse processo. As lutas e as conquistas devem, portanto, movimentar-se nos limites da propriedade privada, concebido pelas políticas educacionais, como o chão natural das relações entre os homens.

O indivíduo, nesse contexto, deve "posicionar-se de maneira crítica". Entretanto, tal posicionamento deve ser realizado de forma "responsável e construtiva nas diferentes situações sociais, utilizando o diálogo como forma de mediar conflitos e de tomar decisões coletivas" (PARÂMETROS CURRICULARES NACIONAIS, 1998, p.55). Portanto, ser cidadão é ser responsável e construtivo, no qual o diálogo e o acordo são os caminhos da 
mudança. Sendo assim, desemprego, fome, baixos salários, vida precária, incerta e imprecisa, podem e devem ser resolvidos de forma harmoniosa entre os diversos sujeitos presentes nessa forma de sociabilidade.

As habilidades requeridas no emprego coadunam com as de um cidadão, pois com as “competências exigidas para o exercício da cidadania e para as atividades produtivas, recoloca-se o papel da educação como elemento de desenvolvimento social" (PARÂMETROS CURRICULARES NACIONAIS, 1999, p.26). O desenvolvimento social no Brasil se dará com a construção de indivíduos preparados para a empregabilidade e para a cidadania. A educação assume assim, um papel central na resolução dessa problemática.

Deve-se desenvolver no aluno, de acordo com as Diretrizes Curriculares Nacionais (1999, p.112, grifo do autor), “a política da igualdade", no qual o ponto de partida "é o reconhecimento dos direitos humanos e o exercício dos direitos e deveres da cidadania, como fundamento da preparação do educando para a vida civil". Tomar consciência dos direitos e deveres já alcançados pelos cidadãos de acordo com essa formação é o primeiro passo. Por conseguinte, vê-se necessário a ampliação desses direitos políticos, visto que "a política da igualdade vai se expressar também na busca da equiidade no acesso à educação, ao emprego, à saúde, ao meio ambiente saudável e a outros benefícios sociais", e mais, “[...]no combate a todas as formas de preconceito e discriminação por motivo de raça, sexo, religião, cultura, condição econômica, aparência ou condição física.” (DIRETRIZES CURRICULARES NACIONAIS, 1999, p.112, grifo do autor).

Inicialmente se aprende quais são os direitos instituídos e como usá-los, depois os mecanismos políticos que podem ser ampliados, e por último, são incorporados por cada indivíduo novos valores, atitudes e concepções éticas, que orientem os indivíduos num respeito mútuo entre as diferenças existentes nessa sociedade. A lógica dessa formação é a incorporação dos indivíduos politicamente a estreiteza do espaço do capital. Devemos agir, pensar e lutar pelo caminho da política do estado capitalista, a cidadania desloca a força política do trabalhador fundada no chão social, para o espaço parlamentar controlado pelo capital. Cabe-nos, então, compreender os limites e as possibilidades desse sujeito político sugerido pelos PCN.

As relações de um indivíduo com o outro na construção do todo social na sociabilidade capitalista perde o ponto de vista da totalidade, apresentando-se de forma mistificada como uma relação de indivíduos completamente isolados e ligados uns aos outros 
apenas pelo desejo natural de suprir suas necessidades particulares. No momento em que a sociedade, através das relações sociais, alcança no capitalismo o maior desenvolvimento material e espiritual em relação aos períodos históricos precedentes, produz, da mesma forma, a sociedade civil burguesa que, conforme Marx, "as diversas formas do conjunto social passaram a apresentar-se ao indivíduo como simples meio de realizar seus fins privados, como necessidade exterior" (MARX, 1996, p.26).

Marx, no conjunto de suas obras, se contrapõe radicalmente ao princípio segundo o qual o egoísmo faz parte da natureza do homem, ao constatar que a relação social no modo de produção primitivo, não se fundamentava na exploração do homem pelo homem. O "ser" dos homens, diz, Marx “coincide, pois, com sua produção, isto é, tanto com o que eles produzem quanto com a maneira como produzem. $\mathrm{O}$ que os indivíduos são depende, portanto, das condições materiais da sua produção" (MARX, 2002, p.11).

Ao não historicizar a vida prática dos homens, naturalizando como lei eterna o egoísmo entre os indivíduos, a sociabilidade do capital aponta como a única possibilidade de uma vida genérica dos homens, o Estado. Dito por outras palavras, a participação dos indivíduos entre si deverá ser mediada pelo espaço da política, a construção de cidadãos políticos garante a cada indivíduo um lugar sem os conflitos da vida privada. Essa mistificação de vida coletiva em favor do capital aprisiona a força social ao chão real em que se assenta, já que o Estado capitalista "brota da natureza a-social desta vida civil, dessa propriedade privada, desse comércio, dessa indústria, dessa rapina recíproca das diferentes esferas civis [...]" (MARX, 1995, p.80).

O Estado, na compreensão de Marx, não transcende a vida privada da sociedade burguesa, mas ao contrário, a mantém, complementando sua viabilidade econômica, política e social. Mészáros, complementando, afirma que o Estado atua como uma "estrutura totalizadora de comando político do capital" (2002, p.106). Portanto, o Estado se eleva como uma estrutura jurídica e política dependente ontologicamente da matriz do ser social, que é a economia, ou ainda, as relações de produção. Essa dependência não pode ser rebaixada a uma compreensão do Estado como algo que surge, diretamente ou mecanicamente, da base econômica, mas sim de "uma relação entre fundante e fundado em nível de ser. [...] o Estado encontra a sua razão última de ser, a sua essência, na sociedade civil e expressa esta razão de ser. E que, nesse sentido, nenhuma inversão é possível". (TONET, 1995, p.55). 
O surgimento do Estado moderno como algo intrinsecamente relacionado ao modo de produção do capital tem como uma de suas funções o controle político e legal que permite a continuidade da dominação do capital sobre o trabalho assalariado.

A negatividade da função do Estado configura-se em um poder político que não pode ir além das determinações últimas de uma sociedade de classes. Esse poder com todas as suas possibilidades sociais de sanar alguns problemas de forma temporária e superficial dos efeitos do capital, manifesta-se impotente em relação aos imperativos destrutivos provocados pela "escravidão social dos produtores de riqueza pelos seus apropriadores, e a dominação econômica sobre o trabalho" (MÉSZÁROS, 2002, p.576).

Não podemos negar, contudo, que as conquistas alcançadas pela sociedade civil no capitalismo foram imensamente maiores que as relações políticas naturalizadas da sociedade feudal, em que os privilégios se resumiam a uma pequena parcela da população que era constituída pela nobreza, deixando a imensa maioria alheia às decisões políticas de sua época. Com a instauração da sociabilidade do capital, abre-se a possibilidade da emancipação política como o patamar mais alto e possível nessa forma de sociedade. Contudo, a comunidade política num Estado economicamente desenvolvido conforme Marx seria no limite:

A vida genérica do homem em oposição a sua vida material. Todas as premissas desta vida egoísta permanecem de pé à margem da esfera estatal, na sociedade civil, porém, como qualidade desta. Onde o Estado político já atingiu seu verdadeiro desenvolvimento, o homem leva, não só no plano do pensamento, da consciência, mas também no plano da realidade, da vida, uma dupla vida: uma celestial e outra terrena, a vida na comunidade política, na qual ele se considera um ser coletivo, e a vida na sociedade civil, em que atua como particular; considera outros homens como meios, degrada-se a si próprio como meio e converte-se em joguete de poderes estranhos. O Estado político conduz-se em relação à sociedade civil de modo tão espiritualista como o céu em relação à terra. (MARX, 1991, p.26).

O desenvolvimento expresso pelos direitos civis, políticos e sociais do cidadão não consegue em relação às determinações desumanizadoras do poder social do capital ir à raiz dos problemas em que a humanidade sofre ainda hoje. Assim, a comunidade política ou a cidadania repousa sobre a vida civil burguesa, deita-se sobre uma vida prática alienadora, em que a liberdade se configura numa liberdade do comércio; a igualdade restringe-se a igualdade legal entre os homens, e a fraternidade resume-se a uma moral fundamentada na caridade entre os indivíduos. 
A vida política, de forma abstrata, tenta dissolver a fratura ineliminável da vida civil burguesa. Os homens, na vida cotidiana, têm como base natural o interesse particular e egoísta. Os indivíduos deverão conquistar sua generidade na participação do espaço político, onde sua vida real imediata é mantida como algo transponível apenas de forma alegórica, ilusória e fantasiosa por meio da cidadania. Marx (1991, p.50) completa: “A emancipação política é a redução do homem, de um lado, a membro da sociedade burguesa, a indivíduo egoísta independente e, de outro, a cidadão do Estado, a pessoa moral".

Os cidadãos devem mover-se por direitos e deveres conquistados politicamente e normatizados pelo Estado. Tais direitos não podem ultrapassar o princípio essencial da sociabilidade burguesa e somente de maneira negativa e formal conservam a opressão de classe. A vida genérica do homem, na cidadania, coloca-se sob a escravidão do homem egoísta burguês. Corroborando com essa afirmação Marx afirma que

\begin{abstract}
Nenhum dos chamados direitos humanos ultrapassa, portanto, o egoísmo do homem, do homem como membro da sociedade burguesa, isto é, do indivíduo voltado para si mesmo, para seu interesse particular, em sua arbitrariedade privada e dissociado da comunidade. Longe de conceber o homem como um ser genérico, estes direitos, pelo contrário, fazem da própria vida genérica, da sociedade, um marco exterior aos indivíduos, uma limitação de sua independência primitiva. $O$ único nexo que os mantém em coesão é a necessidade natural, a necessidade e o interesse particular, a conservação de suas propriedades e de suas individualidades egoístas. (MARX, 1991, p.44)
\end{abstract}

A comunidade na qual o homem, através da política, está inserido na sociabilidade do capital, é uma comunidade parcial, pois não pode transpassar a exploração do homem pelo homem.

A constituição de um trabalhador-cidadão instaura a consciência de uma ação política como possibilidade de reformar, ampliar ou garantir seus direitos no sistema do capital. Contudo, na política, a vida genérica do homem é uma falsidade que o oprime e uma condição para ser explorado de forma justificada pelo Estado. Marx, de forma categórica, explicita esta questão:

Portanto, ainda segundo Marx, a emancipação humana é radicalmente oposta à emancipação política, pois agarra o homem em sua totalidade social, parte da sua essência que é sua vida real; dessa forma, o olhar sobre esse homem parte de um horizonte inatingível pela parcialidade da política numa sociedade de classe. A emancipação humana alcança o homem que trabalha e que, no trabalho assalariado do capital, é separado de sua vida genérica. A 
emancipação humana é a libertação do homem da escravidão do trabalho alienado e de uma vida genérica ilusória do Estado. É o início da verdadeira história da humanidade, no qual o trabalho é uma condição para a liberdade, transformando as relações humanas numa verdadeira condição de crescimento e desenvolvimento das capacidades e potencialidades de cada indivíduo.

A emancipação humana precisamente não vem a ser um paraíso na terra, no qual a sociedade é um todo homogêneo sem nenhum tipo de problema ou contradição; mas de acordo com Marx, um lugar em que "o livre desenvolvimento de cada um é a condição para o livre desenvolvimento de todos" (MARX, 1998, p.31).

Todavia, a emancipação humana só se efetiva numa outra forma de sociabilidade para além do capital. O capital, constituído por uma força totalizadora que atua sobre todo conjunto das relações sociais, econômicas e políticas. Pode apenas ser transformado por uma força do mesmo molde social e universal que se situe radicalmente em oposição ao capital. Nesse sentido, apenas o trabalho, com o seu homem ativo, o proletário, pode realizar essa tarefa histórica e, através de uma revolução social, instaurar uma nova forma de sociabilidade.

Uma transformação dessa natureza não pode partir por um ato de vontade, mas de condições e possibilidades concretas, em que o desenvolvimento das forças produtivas, aliado a uma consciência do proletariado em relação a sua vida explorada, o impulsione a realizar a sua libertação a partir de uma ação radical sobre essas condições sociais, econômicas e políticas as quais está aprisionado.

A contribuição da política na revolução, de acordo com Marx, é o primeiro passo para "ir arrancando todo o capital das mãos da burguesia, para centralizar todos os instrumentos de produção nas mãos do Estado, isto é, do proletariado organizado como classe dominante, e para aumentar o mais rápido possível a massa das forças produtivas" (MARX, 1998, p.29)

A emancipação política, ou seja, a cidadania, como vimos, não se contrapõe ao capital, ao contrário, serve de alma genérica a um homem destituído de sua vida real, afastando-o dos outros homens e dele mesmo, pois o que prevalece nessa relação é a produção de mercadoria, é o valor de troca. Do contrário, a emancipação humana coloca como perspectiva a construção da verdadeira comunidade humana, da qual o homem "tenha organizado suas próprias forças como forças sociais e quando, portanto, já não separa de si a 
força social sob a forma de força política, somente então se processa a emancipação humana." (MARX, 1991, p.52).

\section{OS PCN E A PRESSUPOSIÇÃO DO TRABALHADOR-CIDADÃO-CONSUMIDOR COMO SUJEITO DA SOCIEDADE DE MERCADO}

Do mesmo modo que a cidadania, a formação, na perspectiva da empregabilidade, demanda mais uma esfera de qualificação desse "novo" indivíduo na sociedade do capital em crise. O mercado consumidor transformou-se em outro locus das "lutas e conquistas" dos indivíduos contra os "excessos" do capital. O consumidor deve capacitar-se de informação sobre seus direitos, exigir qualidade e segurança alimentar para seus alimentos. O capital, por esse meio, envolve os indivíduos aos espaços controlados e inerentes a essa forma de reprodução social.

Os Parâmetros Curriculares Nacionais do Ensino Fundamental (1998) têm em um dos seus tópicos, os Temas Transversais (1998). Os Temas Transversais têm "o compromisso com a construção da cidadania [...], sendo voltados para a "compreensão da realidade social, dos direitos e responsabilidades em relação à vida pessoal e coletiva e a afirmação do princípio da participação política" (TEMAS TRANSVERSAIS, 1999, p.17). Portanto, por meio desses temas, poderemos compreender as possibilidades e os caminhos de mudança sugeridas por essas políticas educacionais numa sociedade de mercado.

Os Temas Transversais são organizados em seis tópicos, a saber: Ética, Pluralidade Cultural, Meio Ambiente, Saúde, Orientação Sexual, Trabalho e Consumo. Dos tópicos citados, iremos analisar a temática "Trabalho e Consumo", visto haver uma relação direta com o nosso objeto de pesquisa que é a formação para a empregabilidade.

A orientação dada pelos Temas Transversais (1999, p.17) é que esses temas devem ser "incorporados nas áreas já existentes e no trabalho educativo da escola". Portanto, não se trata de novas disciplinas ou áreas criadas pelos documentos, mas de problemáticas que devem perpassar todas as disciplinas e envolver o trabalho escolar, na perspectiva de contribuir para repensar o currículo e acrescentar novas questões à vida escolar dos alunos.

O termo Trabalho e Consumo pressupõe o estabelecimento de uma relação entre o trabalhador, o cidadão, o consumidor e a sociabilidade capitalista. A compreensão dessa 
relação pode esclarecer o papel em que cada trabalhador-cidadão-consumidor ocupa nas relações do mercado capitalista da atualidade.

Trabalho, para os Temas Transversais (1999, p.343), constitui-se nas "relações que os seres humanos estabelecem entre si e com a natureza, de caráter econômico, político, cultural, produzem modos de ser e de viver [...], e por conseguinte, "definem, a cada momento, o que será considerado imprescindível ao bem viver." A atividade humana deve ser entendida em toda a sua rede de relações sociais e econômicas em que são produzidas, distribuídas e consumidas.

Uma das críticas que o tema "Trabalho e Consumo" (1999, p.343) realiza é a existência da falta de liberdade dos indivíduos em escolher no que quer trabalhar, e o que quer consumir, já que a desigualdade nessas esferas ocorre pela má distribuição dos bens produzidos e dos empregos disponíveis.

Consumir, dizem os documentos, "não é um ato 'neutro' [...]", pois:

significa participar de um cenário de disputas por aquilo que a sociedade produz e pelos modos de usá-los, tornando-se um momento em que os conflitos, originados pela desigual participação na estrutura produtiva, ganham continuidade por meio da distribuição e apropriação de bens e serviços (TEMAS TRANSVERSAIS, 1999, p.343).

O sujeito político deve se organizar na luta por seus direitos. A construção da cidadania se dirige por um caminho de lutas em prol da afirmação dos "direitos ligados à liberdade, à participação nas decisões públicas e à igualdade de condições dignas de vida, modificando, dessa forma, a distribuição de riqueza e poder na sociedade" (TEMAS TRANSVERSAIS, 1999, p.343). A esfera da distribuição apresenta-se, de acordo com esse discurso, no único lugar possível a ser modificado. O mercado representaria um espaço de disputas, em que os consumidores por meio da educação, apreenderiam seus direitos e, de forma ativa, participariam das esferas públicas no objetivo da ampliação e cumprimento desses benefícios garantidos pelo Estado.

A educação tem um papel essencial na construção de indivíduos cientes da importância de sua participação nas relações políticas. Deve-se lutar por uma sociedade "[...] democrática e não excludente” (TEMAS TRANSVERSAIS, 1999, p.343). 
Conforme os Temas Transversais (1999, p.344), a educação pode colaborar garantindo "aos alunos sólida formação cultural, favorecendo o desenvolvimento de conhecimentos, habilidades e atitudes de cooperação, solidariedade e justiça [...]," que contribuam, “[...] para a formação de uma consciência individual e coletiva dos significados e contradições presentes no mundo do trabalho e do consumo, das possibilidades de transformação". Os trabalhadores-consumidores devem, de maneira consciente, perceber, enquanto proprietário de si mesmos, que cooperam com a produção capitalista e, por isso, usar da solidariedade nas relações com os outros integrantes desse sistema produtivo e, por fim, exigir preços, qualidades e atendimentos justos na realização do consumo.

O aprendizado voltado para a construção de um consumidor consciente dos seus direitos e do seu poder sobre o capital pode ser exemplificado em alguns pontos demonstrados pelos PCN: deve-se defender o trabalho formal, exigindo a carteira assinada, pedir a nota fiscal no ato da compra, garantindo assim ao Estado sua arrecadação para fins sociais e, ao consumidor, o direito a reclamações sobre o produto adquirido na compra, como também, a postura crítica para exigir a segurança alimentar, observando a validade e a garantia na qualidade dos alimentos. Essas e outras questões trabalhadas pelas escolas estimularão nos educandos atitudes responsáveis e críticas sobre as esferas do trabalho e do consumo. Conhecer e praticar os direitos do trabalhador e do consumidor, garantidos pelo Estado, de acordo com as políticas em análise, é um dos caminhos que amenizarão as desigualdades sociais no Brasil. Verificamos algumas dessas questões na citação abaixo:

\footnotetext{
Os cuidados a serem tomados na compra de alimentos industrializados apontam a necessidade de criação de uma série de hábitos, como a leitura da data de validade, dos rótulos, verificando sua composição nutricional, procedência, a existência de central de atendimento ao consumidor; verificar as condições da embalagem segurança, estado de conservação, preferindo embalagens simples e biodegradáveis , o registro do produto no Ministério de Saúde, exigindo sempre a nota fiscal, o que permitirá a devolução do produto em caso de estar deteriorado; as condições de higiene e armazenamento do produto no local de comercialização. (TEMAS TRANSVERSAIS, 1998, p.388).
}

Os consumidores, portanto, devem assumir o lugar de sujeito transformador, uma vez que "os cidadãos ainda desconhecem sua força como consumidores, sua condição de sujeito na relações de consumo, seus direitos e sua capacidade para intervir nessas relações" (TEMAS TRANSVERSAIS, 1999, p.353). Nesta ótica, o consumidor torna-se um dos sujeitos principais nas transformações necessárias à sociedade, pois 
repúdio à exploração e precarização das relações de trabalho, às desigualdades e discriminações de gênero, etnia e idade, assim como a defesa de direitos em relação ao meio ambiente e à saúde (TEMAS TRANSVERSAIS, 1999, p. 354).

Segundo o referido documento, a educação deve ser desenvolvida na perspectiva de

[...] propiciar aos alunos o desenvolvimento de capacidades que lhes permitam compreender sua condição de consumidor, com os conhecimentos necessários para construir critérios de discernimento, atuar de forma crítica, perceber a importância da organização, solidariedade e cooperação para fazer valer seus direitos e assumir atitudes responsáveis em relação a si próprio e à sociedade (TEMAS TRANSVERSAIS, 1999, p.354).

A partir desse discurso, a política do Estado pode propor ao capital um modelo de desenvolvimento mais humano, e o consumidor-cidadão consciente, através do seu poder de escolha do que comprar ou não comprar, irá impor ao capital restrições a sua produção destrutiva.

A liberdade defendida por esse corpo legal educativo (PCN), encaixa-se inteiramente nas relações do mercado capitalista no qual indivíduos isolados e autônomos se relacionam num mundo abstratamente construído socialmente, visto que as relações desses seres individualmente egoístas, só serão possíveis, numa coletividade imaginária. Sua relação como ser genérico só pode se dar de forma política, através da cidadania ou como consumidor: duas maneiras de relações coletivas que os homens se relacionam de forma amorfa, pois são comunidades em que os homens se perdem em favor da auto-reprodução do capital.

A respeito dessa questão, Tonet diz o seguinte: "o que anula a liberdade é a própria existência do mercado e de sua expressão política que é o Estado". (TONET, 2004, p.62). Continuando, o autor afirma que "onde o mercado, mesmo disciplinado, rege a vida social, é o capital que comanda e onde manda o capital, quem é livre não é o trabalho vivo, o homem concreto, mas o trabalho morto" (TONET, 2004, p.62). Fazendo um trocadilho com Machado de Assis (2003, p.47), que afirma no seu conto "O Espelho" que "o alferes eliminou o homem", podemos admitir que o mercado eliminou o homem real, sobrando apenas sua capacidade de trabalho, homogeneizada e quantificada, a qual o capital se apropria para seu interesse inumano.

De acordo com Tonet, o problema está na forma como os homens se organizam no processo do trabalho: 
O que o homem está perdendo neste processo é o domínio consciente sobre a sua própria objetivação. Não perde apenas o acesso aos bens por ele produzidos - acesso permitido em parte e pequena parcela da humanidade. Ele se vê expropriado de muito mais: de reger, com consciência e liberdade, o processo de autoconstrução. É como se - e é isto que de fato acontece, enquanto o processo é regido pelo capital sua entificação fosse dirigida por outro ser, por outra vontade que não a sua. As conseqüências disto são brutais: a mais plena perversão do seu próprio ser, do mundo por ele criado e das relações entre os homens. (TONET, 2004, p.61-62).

Vale lembrar, para colocar as coisas em seus devidos lugares que, conforme Marx (2001, p.5), "El objeto a considerar es en primer término la producción material”, ou melhor, “indivíduos que producen en sociedad, o sea la produccíon de los individuos socialmente determinada: este es naturalmente el punto de partida". O trabalho, nesse instante de crise, deve ser reposto teórica e praticamente como o ponto de partida, ou seja, voltado para a compreensão e superação da ordem do capital. Portanto, lutar por uma formação em que se construa de forma fragmentária um trabalhador-cidadão-consumidor é, como afirma Tonet (2004, p.71), interditar e estacionar a vida humana à barbárie de uma sociedade da mercadoria.

\section{REFERÊNCIAS}

BRASIL, Referenciais para a formação de professores / secretaria de educação fundamental. Brasília, 1999.

BRASIL. Ministério da Educação. Secretária de Ensino Fundamental. Parâmetros Curriculares Nacionais: História e Geografia. Brasília, 1997.

Parâmetros Curriculares Nacionais do Ensino Fundamental. Brasília, 1998.

BRASIL, MEC/SEMT, Parâmetros Curriculares Nacionais do Ensino Médio. Brasília, 1999.

OLIVEIRA, R. A (des)qualificação da educação profissional brasileira. São Paulo: Cortez, 2003.

MARX, Carlos. Trabajo asalariado y capital. Barcelona: Nova Terra, 1970.

MARX, K.; ENGELS, F. A ideologia alemã - Teses sobre Feuerbach. São Paulo: Moraes, 1984.

Manifesto do partido comunista. São Paulo: Cortez, 1998.

MARX, Karl. A questão judaica. 2a edição, São Paulo: Moraes 1991.

Elementos fundamentales para la crítica de la economia política (Grundrisse)

1857-1858. vol 1, México, D.F: Siglo veintiuno, 2001. 
Glosas críticas marginais ao artigo O rei da Prússia e a reforma social. De um prussiano. Tradução Ivo Tonet. Revista Práxis, n.5. Belo Horizonte: Projeto Joaquim de Oliveira, 1995.

Claret, 2002.

Manuscritos econômico-filosóficos. Tradução Alex Marins. São Paulo: Martin

O capital: crítica da economia política. Livro 1, vol. 1. Tradução Reginaldo

Sant'Anna. São Paulo: Civilização Brasileira, 2002.

Para a crítica da economia política. In: Os Pensadores. São Paulo: Nova Cultural, 1996

MÉSZÁROS, I. Para além do capital. São Paulo: Boitempo, , 2002.

TONET, I. Sobre o socialismo. Curitiba: HD Livros, 2002.

Educar para a cidadania ou para a liberdade? Maceió, 22 jun. 2005.

Disponível em: <http:www.geocities.com/ivotonet>. Acesso em: 22 de jun. de 2005.

Democracia ou liberdade?. Maceió: edufal, 2004.

Educação, cidadania e emancipação humana. Marília-SP: mimeo. Tese de Doutourado, 2001. 